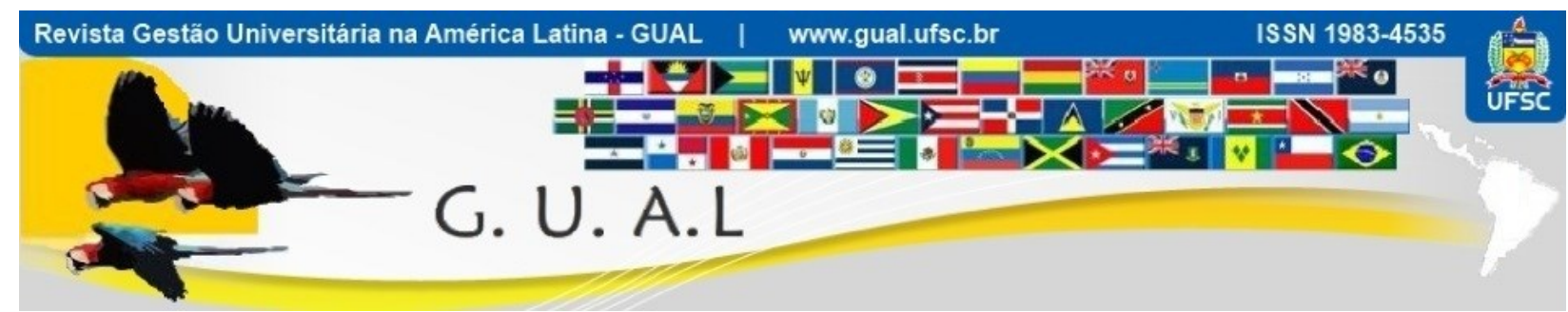

DOI: http://dx.doi.org/10.5007/1983-4535.2018v11n2p222

\title{
A INSTITUCIONALIZAÇÃO DA ACREDITAÇÃO INTERNACIONAL EM ESCOLAS DE GESTÃO E NEGÓCIOS BRASILEIRAS: FATORES DETERMINANTES, PERSPECTIVAS E DESAFIOS
}

\section{THE INSTITUTIONALIZATION OF THE INTERNATIONAL ACCREDITATION IN BRAZILIAN BUSINESS AND MANAGEMENT SCHOOLS: DETERMINANT FACTORS, PERSPECTIVES AND CHALLENGES}

Mauricius Munhoz de Medeiros, Doutorando Universidade Federal do Rio Grande do Sul - UFRGS Centro Universitário FADERGS - Laureate International Universities mauricius.medeiros@gmail.com

Redvânia Vieira Xavier, Doutoranda Universidade do Vale do Rio dos Sinos - Unisinos Universidade Federal do Amazonas (UFAM) red.vania.vieira@gmail.com

Norberto Hoppen, Doutor Universidade do Vale do Rio dos Sinos - Unisinos norbertoh@unisinos.br

Fernando Marcelo Gossler Wawginiak, Mestre Universidade do Vale do Rio dos Sinos - Unisinos fernandomgw@hotmail.com

\section{Aline Caye, Mestra Universidade do Vale do Rio dos Sinos - Unisinos linecaye@gmail.com}

Recebido em 20/dezembro/2017

Aprovado em 12/abril/2018
Sidnei de Moura Lisboa, Mestre Universidade do Vale do Rio dos Sinos - Unisinos

Artigo apreciado pela modalidade Fast-Track - XX SemeAD

simagio@hotmail.com

Sistema de Avaliação: Double Blind Review

Esta obra está sob uma Licença Creative Commons Atribuição-Uso. 


\title{
RESUMO
}

A acreditação internacional de uma Instituição de Ensino Superior (IES) confere-lhe uma chancela de qualidade em educação reconhecida internacionalmente. Ela é obtida após um processo relativamente longo de evidenciação da qualidade dos processos de ensino e aprendizagem, e do impacto da sua pesquisa e ação profissional. O processo de acreditação internacional provoca, nas IES, uma mudança institucional para adaptação às regras da acreditadora. A pesquisa tem como objetivo analisar os fatores determinantes, os desafios e as perspectivas da institucionalização da acreditação internacional, em Escolas de Gestão e Negócios (EGN), no Brasil. A teoria de base adotada é a institucional e como estratégia, adotou-se o estudo de casos múltiplos, realizado em cinco EGN brasileiras, todas associadas à AACSB. Foram entrevistados 15 envolvidos no processo de acreditação. Evidenciou-se que as pressões isomórficas estão presentes nas razões que motivam a decisão de implementar o processo de acreditação; as pressões coercitivas e miméticas, com um maior número de observações, e as pressões normativas, com um menor número de observações. Identificou-se, também, os desafios de cada etapa do processo de institucionalização, além das perspectivas relacionadas à estratégia de acreditação internacional. Por fim, mapeou-se em quais etapas de institucionalização estão localizadas as EGN estudadas.

Palavras-chave: Acreditação Internacional. Instituições de Ensino Superior (IES). Escolas de Gestão e Negócios (EGN). Institucionalização.

\begin{abstract}
The international accreditation of a higher education institution (HEI) grants it a seal of education quality that is internationally recognized. It is obtained after a relatively long process of disclousure of the teaching and learning processes and of the impact of its research and professional action. The process of international accreditation causes an institutional change in the HEI in order to adapt to the accrediting agency's rules. This research aims at analyzing the determinante factors, the challenges and the perspectives of the institutionalization of international accreditation in Business and Management Schools (BMS) in Brazil. This work is based on the institutional theory and the strategy adopted was the multiple case study, which was carried out in five Brazilian BMS, all of which are members of AACSB. Fifteen people that were involved in the accreditation process were interviewed. It became evident that isomorphic pressures are present in the reasons that motivate the decision to implement the accreditation process; the coercive and the mimetic pressures with a greater number of observations; and the normative pressures, with a lower number of observations. This research also identified the challenges of each stage of the institutionalization process, besides the perspectives related to the strategy of international accreditation. Finally, it was mapped in which stages of institutionalization the studied BMS are.
\end{abstract}

Keywords: International Accreditation. Higher Education Institutions (HEI). Business and Management Schools (BMS). Institutionalization. 


\section{A INSTITUCIONALIZAÇÃO DA ACREDITAÇÃO INTERNACIONAL EM ESCOLAS DE GESTÃO E \\ NEGÓCIOS BRASILEIRAS: FATORES DETERMINANTES, PERSPECTIVAS E DESAFIOS \\ DOI: http://dx.doi.org/10.5007/1983-4535.2018v11n2p222}

\section{INTRODUÇÃO}

As Escolas de Gestão e Negócios (EGN) tornaram-se, nos últimos anos, uma das Instituições de Ensino Superior (IES) que mais crescem e que mais sofrem pressões para agregar valor à sociedade (FRIGA, BETTIS e SULLIVAN, 2003; ANTUNES; THOMAS, 2007; ISTILEULOVA; PELJHAN, 2013). Visando permanecer no mercado competitivo e alcançar seus objetivos, as EGN estão investindo na qualidade da prestação dos serviços como estratégia de negócio. Neste contexto, a acreditação é apontada como um meio para a obtenção da qualidade nos serviços em educação. Porém, por várias razões, como a melhoria da posição nos rankings nacionais e as exigências do mercado, as EGN, ao invés de procurar a acreditação nacional, estão optando pela busca da acreditação internacional (BAILEY, CHOW, HADDAD, 1999; FRIGA, BETTIS e SULLIVAN, 2003).

A acreditação internacional é um processo de certificação externa da qualidade do ensino e da pesquisa de uma IES, que lhe confere uma chancela reconhecida internacionalmente, diferindo do credenciamento necessário à autorização de funcionamento conferida localmente (e. g. conferida a cursos e instituições pelo Ministério de Educação e pela CAPES no Brasil). Este processo é compreendido pelos professores, administradores e alunos como uma iniciativa importante, por vezes prioritária. O processo de acreditação costuma ser longo, pois a instituição precisa mostrar a qualidade dos processos internos a um olhar externo. A acreditação é orientada por um conjunto de etapas reunidos em uma metodologia adotada por uma agência acreditadora e o passo inicial do processo é a instituição tornar-se membro da agência, em geral organizada em forma de associação. As principais associações acreditadoras internacionais de EGN são, respectivamente, a AACSB (Association to Advance Collegiate Schools of Business), a EFMD/EQUIS (European Foundation For Management Development/Quality Improvement System), e a AMBA (Association of MBAs) (ISTILEULOVA; PELJHAN, 2013).

O processo de acreditação internacional busca, de certa maneira, evitar a homogeneização das EGN, ou seja, a determinação de um padrão único de ações e procedimentos para as escolas acreditadas (HANSON, 2001). Nesse sentido, Zhao e Ferran (2016) colocam que as agências exigem que suas associadas possuam uma estratégia que oriente suas ações, de maneira que possam ter flexibilidade para responder às condições de mercado e alcançar sucesso em seu ambiente de atuação. 


\section{A INSTITUCIONALIZAÇÃO DA ACREDITAÇÃO INTERNACIONAL EM ESCOLAS DE GESTÃO E \\ NEGÓCIOS BRASILEIRAS: FATORES DETERMINANTES, PERSPECTIVAS E DESAFIOS \\ DOI: http://dx.doi.org/10.5007/1983-4535.2018v11n2p222}

Utilizando a acreditação da AACSB como exemplo, para iniciar o processo é preciso apresentar à acreditadora um conjunto de atividades no plano formal, reunindo evidências e documentação que fundamentem as atividades. Segue a etapa de elegibilidade. Nesta fase, exige-se que a EGN, já na condição de membro, reporte à acreditadora o conjunto de cursos (graduação, mestrado e doutorado) que será objeto da acreditação. Para submeter-se ao processo de elegibilidade junto à acreditadora, a EGN deve reportar informações sobre seu quadro docente, sua formação, produção cientifica e atividade profissional; e também, reportar informações sobre os seus processos de gestão acadêmicos e não acadêmicos, os valores, e os principios que a movem (AACSB, 2016).

De acordo com a teoria institucional, o processo de adaptação às configurações do ambiente é reconhecido como institucionalização, que ocorre a partir de uma mudança institucional, mudança esta que acontece, geralmente, de maneira incremental. O processo de mudança institucional envolve alterações nas regras formais e informais (NORTH, 1990). Assim, vislumbra-se que o processo de acreditação provoca, nas IES, uma necessidade de adaptação às regras da organização acreditadora, ensejando um esforço institucional para a organização de recursos e uma padronização de processos organizacionais e de negócio. Para atender a tais condições, faz-se imperiosa a formulação e execução de iniciativas estratégicas. Ou seja, para atender aos requisitos da acreditação, as IES empreendem uma mudança estratégica. Na revisão da literatura efetuada nas bases Periódicos Capes, Google Scholar, EBSCO Host e Web of Science, verificou-se que há poucas pesquisas empíricas que tratam deste tema à luz da teoria institucional (ISTILEULOVA; PELJHAN, 2013).

Pensando neste contexto, foram elaboradas as seguintes questões de pesquisa: Quais fatores isomórficos institucionais influenciam a adoção da estratégia de acreditação? $\mathrm{E}$ quais os principais desafios e perspectivas da institucionalização da acreditação internacional na área de gestão e negócios para as IES brasileiras?

Desse modo, a pesquisa tem como objetivo analisar os fatores determinantes, os desafios e as perspectivas da institucionalização da acreditação internacional, em EGN, no Brasil relacionando os desafios e as oportunidades da acreditação e contribuindo fortemente para as instituições que buscam melhorar a qualidade do ensino nivelando-se a padrões internacionais. Pelo fato de abranger múltiplas IES, a pesquisa evidencia experiências de instituições já acreditadas e os desafios de instituições que ainda se encontram no processo de 


\section{A INSTITUCIONALIZAÇÃO DA ACREDITAÇÃO INTERNACIONAL EM ESCOLAS DE GESTÃO E \\ NEGÓCIOS BRASILEIRAS: FATORES DETERMINANTES, PERSPECTIVAS E DESAFIOS \\ DOI: http://dx.doi.org/10.5007/1983-4535.2018v11n2p222}

acreditação. Na sequência, o texto deste artigo está estruturado nos seguintes tópicos: referencial teórico, metodologia, análise e discussão dos resultados e considerações finais.

\section{REFERENCIAL TEÓRICO}

O levantamento das referências bibliográficas foi feito com base nas palavras-chave "acreditação internacional", "teoria institucional" e "educação superior" (em português e inglês), com o propósito de consolidar a base teórica do estudo. Buscou-se o referencial teórico nas bases de dados Periódicos Capes, Google Scholar, EBSCO Host e Web of Science.

\subsection{A ACREDITAÇÃO NAS INSTITUIÇÕES DE ENSINO SUPERIOR (IES)}

Acreditar significa aprovar ou avaliar oficialmente, tornar digno de confiança. Acreditação é um processo de avaliação institucional que objetiva a qualidade da prestação dos serviços, por intermédio de padrões previamente estabelecidos (ALÁSTICO, 2013). Na área da educação, a acreditação é um processo voluntário, não governamental e contínuo de avaliação da qualidade, realizada por uma organização especializada, por meio de critérios explícitos e baseados nas melhores práticas de gestão e qualidade (AACSB, 2016). A acreditação assegura um nível específico de qualidade, conforme a missão da instituição, os objetivos do programa e as expectativas de diferentes atores envolvidos, como os estudantes. O processo de acreditação, normalmente, resulta na concessão de um reconhecimento por um tempo determinado ( $\operatorname{sim}$ ou não, uma pontuação numa escala de vários níveis, uma combinação de qualificação por letras, uma licença de funcionamento ou um reconhecimento condicional adiado) (SANYAL; MARTIN, 2006).

Para Lejeune (2009), baseada em seus critérios específicos, a acreditação permite não somente melhorias relacionadas à eficácia organizacional, como também implicações de cunho cultural. Em contraste, autores como Julian e Dankwa (2006) veem a acreditação como uma ameaça para as EGN mais inovadoras, impedindo que estas tomem iniciativas julgadas necessárias, para se diferenciar em um cenário de constante mudança ambiental. Os autores sugerem, inclusive, que algumas escolas possam, de certa forma, optar por não se tornarem acreditadas e, até mesmo, renunciar ao seu credenciamento.

Conforme apontam Sanyal e Martin (2006), acreditação é o método de garantia de qualidade mais utilizado no contexto internacional; é o resultado de um processo mediante o qual uma entidade pública (governamental) ou privada (agência de acreditação) avalia a 


\section{A INSTITUCIONALIZAÇÃO DA ACREDITAÇÃO INTERNACIONAL EM ESCOLAS DE GESTÃO E \\ NEGÓCIOS BRASILEIRAS: FATORES DETERMINANTES, PERSPECTIVAS E DESAFIOS \\ DOI: http://dx.doi.org/10.5007/1983-4535.2018v11n2p222}

qualidade de uma IES, seus programas ou cursos, com o objetivo de reconhecer formalmente que tal instituição cumpre determinados critérios ou padrões pré-determinados e concederlhes um selo de qualidade (SANYAL; MARTIN, 2006).

Segundo Hedmo (2004) e Harvey (2004), a acreditação tem uma função claramente anunciada de melhoria para as EGN. Não é surpreendente, então, que se afirme que a acreditação tenha relação com a melhoria da eficácia organizacional (ZAMMUTO, 2008). Embora se possa esperar que melhore a qualidade dos programas educacionais, é possível observar que as percepções dos dirigentes enfatizam mais o impacto da acreditação na atratividade e na imagem de sua escola do que com a satisfação dos alunos e seus currículos (LEJEUNE, 2009). Ashworth, Boyne e Delbridge (2009) tem um posicionamento semelhante, afirmando que a acreditação visa alcançar a legitimidade e a aprovação da instituição junto a outras instituições já acreditadas. Lejeune (2009) afirma, ainda, que as dimensões de eficácia que parecem ter sido mais aperfeiçoadas estão ligadas aos recursos das escolas, em especial aos docentes qualificados e aos parceiros acadêmicos. Neste sentido, parece reforçar uma capacidade externa de adquirir e desenvolver recursos estratégicos.

De acordo com Pertschy (2006), o maior objetivo das IES ainda é o reconhecimento pela formação consistente. Para este autor, a gestão eficaz está ligada a diversos fatores internos e externos que dificultam enormemente o seu desempenho conforme a expectativa da sociedade. Tachizawa e Andrade (2006) afirmam que existem estratégias e instrumentos específicos, que variam em função das crenças, dos valores e modos de gestão de cada IES. A implementação de um modelo de gestão estratégica deve ser estruturada sobre a criação de comitês ou grupos de trabalho compostos por técnicos e gestores que ocupem funções chaves na estrutura da IES, para a condução das atividades intrínsecas ao planejamento estratégico (TACHIZAWA; ANDRADE, 2006). Desse modo, a busca pelo reconhecimento, por meio de acreditação internacional, contempla a melhoria da gestão estratégica e operacional das IES.

\subsection{TEORIA INSTITUCIONAL}

A procura por inovação nas instituições pode ocorrer por vários motivos, como, por exemplo, mudanças tecnológicas, mudanças na legislação, imposição do mercado, investimento no conhecimento, custos de transação, negociação entre agentes políticos ou econômicos. O processo de mudança institucional envolve alterações nas regras formais e informais. As mudanças institucionais são originadas a partir da influência de agentes 


\section{A INSTITUCIONALIZAÇÃO DA ACREDITAÇÃO INTERNACIONAL EM ESCOLAS DE GESTÃO E \\ NEGÓCIOS BRASILEIRAS: FATORES DETERMINANTES, PERSPECTIVAS E DESAFIOS \\ DOI: http://dx.doi.org/10.5007/1983-4535.2018v11n2p222}

políticos ou econômicos, com capacidade e poder de decisão e são determinadas pelas oportunidades percebidas, seja por mudanças externas ou pelo conhecimento e habilidade desses agentes. Este processo de adaptação às mudanças e inovações ocorridas no ambiente organizacional é reconhecido como institucionalização (NORTH, 1990).

Para North (1990) a teoria da mudança institucional não apenas proporciona uma moldura para a história econômica, como também explica de que forma o passado influencia o presente e o futuro. Este processo é caracterizado como contínuo, lento e gradativo, embora passível de rupturas e descontinuidade (BELL, 2011). Portanto, trata-se de uma alteração da matriz institucional imposta pela interação humana, em amplo contexto, com a intenção de produzir resultados benéficos e inovadores para a sociedade.

A institucionalização dessas mudanças ocorre em três etapas: habitualização, objetificação e sedimentação (TOLBERT; ZUCKER, 1999). Para compreender melhor as etapas da institucionalização, apresenta-se a Figura 1, a seguir.

Figura 1 Etapas do Processo de Institucionalização

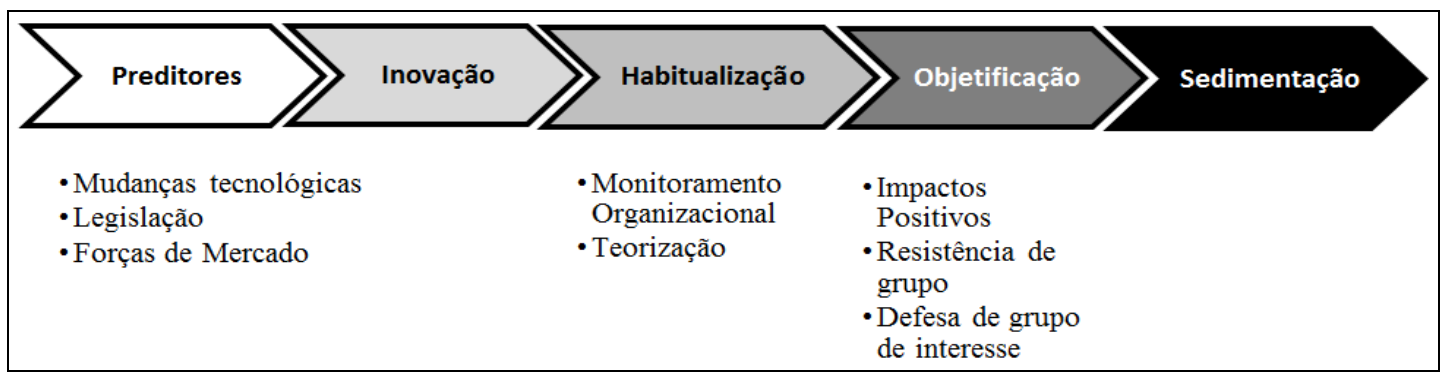

Fonte: Elaborado pelos autores.

Para DiMaggio et al (1991), as mudanças institucionais ocorrem pelo fato de as organizações sofrerem diversos tipos de pressões. Os autores frisam que quando uma empresa reproduz um modelo, processo ou postura de outra, para obter maior visibilidade competitividade ou legitimidade no mercado, está passando pelo processo de isomorfismo organizacional, que pode ser subdivido em competitivo e institucional.

DiMaggio e Powell (2005) identificaram três mecanismos que dão origem às mudanças isomórficas institucionais: a) coercitivo; b) mimético; e c) normativo. O coercitivo, conforme os autores, deriva de influências políticas, do problema da letimidade, de pressões formais e informais - exercidas sobre as organizações, por outras organizações das quais dependem, e também pelas expectativas culturais da sociedade em que elas atuam. Em relação ao isomorfismo mimético, DiMaggio e Powell (2005) colocam que este resulta de respostas 


\section{A INSTITUCIONALIZAÇÃO DA ACREDITAÇÃO INTERNACIONAL EM ESCOLAS DE GESTÃO E \\ NEGÓCIOS BRASILEIRAS: FATORES DETERMINANTES, PERSPECTIVAS E DESAFIOS \\ DOI: http://dx.doi.org/10.5007/1983-4535.2018v11n2p222}

padronizadas à incerteza. Os autores descrevem que a incerteza encoraja a imitação, seja quando as tecnologias organizacionais não são compreendidas suficientemente, seja quando as metas são ambíguas, ou quando o ambiente cria uma incerteza simbólica. Nesses casos, as organizações podem tomar outras como modelo. Já o isomorfismo normativo deriva, geralmente, da profissionalização, que pode ser interpretada como "a luta coletiva de membros de uma profissão para definir as condições e os métodos de seu trabalho" (LARSON e LARSON, 1979, p. 49-52 apud DIMAGGIO e POWELL, 2005, p. 79). DiMaggio e Powell, 2005 chegam à conclusão de que, apesar desses três mecanismos se misturarem no contexto empírico, eles tendem a derivar de condições diferentes, podendo levar a resultados distintos.

Conforme Crubellate, Grave e Mendes (2004), a perspectiva estratégica e a da teoria institucional em organizações vêm sendo entendidas como abordagens que não se comunicam e chegam a ser excludentes. Entretanto, os autores mencionam que vários estudos recentes partem da teoria institucional na tentativa de entender fenômenos vinculados ao pensamento estratégico em organizações. Com isso, a aceitação dos padrões institucionais e dos padrões estratégicos está aumentando no âmbito da teoria organizacional. Salientam, inclusive, que a análise organizacional se beneficia do esforço conjuto da perspectiva estratégica e da perspectiva da teoria institucional, bem como de cada uma delas separadamente, em vários aspectos.

A estratégia organizacional é, tradicionalmente, pensada como fruto da racionalidade e da intencionalidade de decisores organizacionais (ACKOFF, 1983), sendo a adaptação racional da organização reportada a conjuntos externos e a condições ambientais. Porém, para Crubellate, Grave e Mendes (2004), a visão tradicional é cada vez mais confrontada por perspectivas menos voluntaristas sobre a natureza do pensamento estratégico, buscando entendê-lo como desenvolvimento de processos mais ou menos involuntários de cognição, de relacionamento cultural, de negociação política ou de respostas pouco padronizadas em relação às contingências imediatas de uma realidade complexa e mutável. 


\subsection{MODELO E PROPOSIÇÕES DA PESQUISA}

A partir do referencial teórico, desenvolveu-se um modelo conceitual que visa explicar como ocorre o processo de institucionalização da acreditação internacional nas EGN das IES brasileiras. A Figura 2 ilustra este modelo, o qual está sustentado pelas proposições definidas a seguir.

Figura 2 Modelo Conceitual de Pesquisa

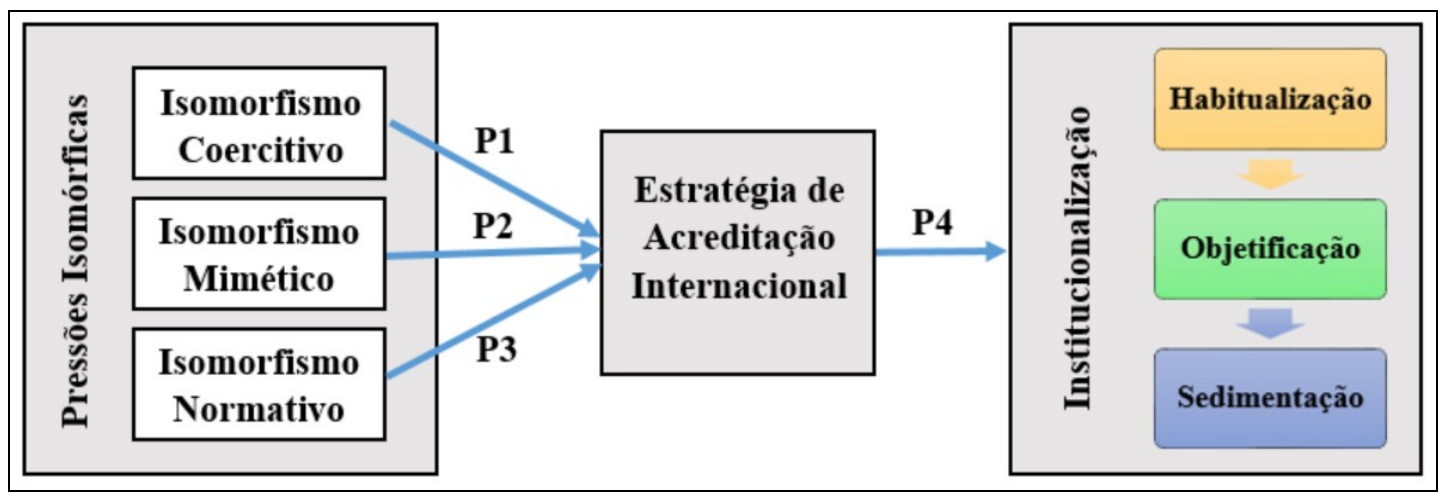

Fonte: Elaborado pelos autores.

Com base no modelo conceitual, por meio das relações teóricas entre os constructos desta pesquisa, foram elaboradas as seguintes proposições:

P1: A busca por legitimidade, distinção e reconhecimento pela comunidade em nível global (isormofismo coercitivo) influencia as EGN brasileiras a adotarem uma estratégia de acreditação internacional.

P2: A existência de um expressivo contingente de EGN, disseminadas globalmente, que tem adotado os padrões internacionais de instituições acreditadoras (isomorfismo mimético), influencia as EGN brasileiras a adotarem uma estratégia de acreditação internacional.

P3: A busca coletiva dos profissionais da EGN por desenvolvimento profissional e qualificação dos métodos de trabalho, associada aos benefícios do estabelecimento de parcerias estratégicas com outras instituições (isomorfismo normativo), influencia as EGN brasileiras a adotarem uma estratégia de acreditação internacional.

P4: Uma vez adotada a estratégia de acreditação, a institucionalização transcorre por meio de um processo que contempla as etapas de habitualização, objetificação e sedimentação. 


\section{A INSTITUCIONALIZAÇÃO DA ACREDITAÇÃO INTERNACIONAL EM ESCOLAS DE GESTÃO E \\ NEGÓCIOS BRASILEIRAS: FATORES DETERMINANTES, PERSPECTIVAS E DESAFIOS \\ DOI: http://dx.doi.org/10.5007/1983-4535.2018v11n2p222}

\subsection{ESTUDOS RELACIONADOS SOBRE A ACREDITAÇÃO INTERNACIONAL EM EGN}

Cooper, Parkes e Blewitt (2014) realizaram um estudo de caso em uma grande EGN do Reino Unido. A pesquisa examinou o papel que a acreditação de EGN pode desempenhar no aumento das contradições institucionais e, portanto, promover a mudança organizacional para o envolvimento das partes interessadas e o engajamento com questões de responsabilidade social e sustentabilidade. Os resultados evidenciaram que um dos fatores que determinam a busca pelas acreditações internacionais das EGN foi a internacionalização. O estudo forneceu algumas evidências para apoiar a afirmação de Scott (1995) de que a acreditação é um importante "mecanismo normativo" que pode levar à mudança institucional e ao isomorfismo.

Roller, Andrews e Bovee (2010) realizaram uma pesquisa Survey com 122 reitores e decanos de EGN acreditadas e não acreditas pela AACSB, pela ACBSP (Accreditation Council for Business Schools and Programs), pelo IACBE (IACBE - International Assembly for Collegiate Business Education). O objetivo da pesquisa foi examinar os custos e benefícios da acreditação e motivação das escolas para buscá-la. Os resultados desta pesquisa evidenciaram alguns benefícios da acreditação. Os mais significativos foram: responsabilidade pelo melhoramento do programa; vantagens de comercialização; vantagens de recrutamento do corpo docente; alavancagem na obtenção de recursos universitários; reconhecimento como uma instituição superior; e, oportunidades para compartilhar técnicas, sucessos e desafios com outras instituições que enfrentam problemas semelhantes. E como benefícios menos significativos foram identificados: reputação na comunidade de negócios; excelência do ensino em sala de aula; atividade acadêmica do corpo docente; desenvolvimento profissional do corpo docente; reputação acadêmica do programa; sobrevivência do programa; e, recrutamento (ROLLER; ANDREWS; BOVEE, 2010).

Miles et al (2014) realizaram um estudo com propósito de prospectar as implicações da atualização dos padrões da AACSB em 2013. A pesquisa foi realizada com decanos que atuam como mentores da AACSB no processo de acreditação de outras EGNs. Os autores identificaram que um dos principais deveres dos decanos é assegurar que os membros do corpo docente tenham recursos adequados para realizar a missão da escola. Além disso, os decanos podem moldar a cultura da EGN, porém eles enfrentam resistências institucionais às 


\section{A INSTITUCIONALIZAÇÃO DA ACREDITAÇÃO INTERNACIONAL EM ESCOLAS DE GESTÃO E \\ NEGÓCIOS BRASILEIRAS: FATORES DETERMINANTES, PERSPECTIVAS E DESAFIOS \\ DOI: http://dx.doi.org/10.5007/1983-4535.2018v11n2p222}

mudanças, como, por exemplo, as de pessoal (professores e demais colaboradores), o reposicionamento da estratégia da universidade e, até mesmo, o contexto econômico.

Istileulova e Peljhan (2015) realizaram um estudo de caso múltiplo em três EGN da Lituânia. O objetivo era explorar e desvendar as razões e as consequências da acreditação, utilizando a Teoria Institucional como base. Os resultados apontaram que nas EGN estudadas, as parcerias internacionais, o reconhecimento internacional e a atratividade de mais estudantes foram as razões citadas pelas IES para a tomada de decisão de institucionalizar a acreditação internacional. A pesquisa identifica que os efeitos de acreditação representam um caso de isomorfismo institucional, porque as EGN requerem a acreditação para alcançar legitimidade ao invés de melhorar o desempenho, e que decidem implementá-la por causa do efeito adesão e para redução da assimetria, e, segundo as autoras, estas razões são acompanhadas por todos os três tipos de pressões isomórficas - coercitivo, mimético e normativo (ISTILEULOVA; PELJHAN, 2015).

Colby, Lambert e McGee (2016) elaboraram um estudo de caso qualitativo, conduzido em uma universidade de médio porte. Foram entrevistados 13 decanos de programas de pósgraduação. O objetivo foi entender como os programas de pós-graduação utilizam práticas colaborativas de apoio à tomada de decisões. Um dos principais resultados aponta que há necessidade de criação de sistemas de avaliação que apoiem a aprendizagem dos alunos, a qualidade e a melhoria contínua do programa. Ademais, enfatiza a importância do engajamento dos professores e administradores na adesão ao protocolo para o que o sistema de avaliação seja mais eficiente.

Por fim, estudo de caso de Hasbun e Rudolph (2016) teve por objetivo discutir as experiências de um programa de pós-graduação no processo de acreditação, evidenciando os desafios enfrentados e as lições aprendidas nesse processo. Os achados dessa pesquisa indicam que, apesar do processo de acreditação ser assustador e demorado, ele é um elemento-chave para muitas instituições. Informam ainda que, independente do sistema adotado, para que seja benéfico para todos os envolvidos, é imperativo que os líderes e os participantes sejam reflexivos, críticos e interativos durante este processo. 


\section{METODOLOGIA}

Como estratégia de pesquisa, adotou-se o estudo de casos múltiplos (YIN, 2015), realizado em cinco EGN brasileiras. O estudo foi desenvolvido em EGN que possuem e/ou que estão em processo de implantação da acreditação internacional em educação na área de gestão e negócios. Com isso, identificou-se que as associações acreditadoras de EGN principais são: AACSB (Association to Advance Collegiate Schools of Business), ACBSP (Accreditation Council for Business Schools and Programs), IACBE (International Accreditation Council for Business Education), EFMD/EQUIS (European Foundation For Management Development/Quality Improvement System), e AMBA (Association of MBAs), esta última não contemplando cursos de graduação e de doutorado (ISTILEULOVA; PELJHAN, 2013; ZHAO; FERRAN, 2016).

Optou-se por investigar as EGN brasileiras associadas à AACSB, por ser uma das mais reconhecidas internacionalmente e por divulgar, em seu sítio eletrônico, quais as instituições associadas. Nesta lista da AACSB, observou-se um total de 11 EGN para o processo de seleção das instituições a serem estudados. Na seleção, primou-se por cinco EGN, que estavam em diferentes estágios do processo de acreditação,localizadas nas regiões sul e sudeste do país. Quatro entidades são privadas e uma pública. Dentre essas, duas já são acreditadas, duas estão desenvolvendo seu processo de acreditação, e uma está iniciando o processo de acreditação. No Quadro 1 foi elaborado um breve resumo que descreve as características das entidades investigadas nesta pesquisa:

Quadro 1 Resumo das características das entidades investigadas

\begin{tabular}{|c|c|c|c|c|c|c|}
\hline EGN & Cursos & Tipo & Fundação & $\begin{array}{c}\mathbf{N}^{\mathbf{0}} \text {. de } \\
\text { alunos }\end{array}$ & Situação & UF \\
\hline A & $\begin{array}{c}\text { Graduação (administração } \\
\text { de empresas, administração } \\
\text { pública, direito e economia). } \\
\text { Pós-graduação lato e stricto } \\
\text { sensu. }\end{array}$ & Privada & 1944 & 6.246 & Acreditada & SP \\
\hline B & $\begin{array}{c}\text { Graduação (negócios, } \\
\text { economia, direito, } \\
\text { engenharia mecânica, } \\
\text { engenharia mecatrônica e } \\
\text { engenharia da computação). } \\
\text { Pós-graduação lato e stricto } \\
\text { sensu. }\end{array}$ & Privada & 1987 & 6.587 & Acreditada & SP \\
\hline C & $\begin{array}{c}\text { Graduação (mais de 50 } \\
\text { cursos). Educação }\end{array}$ & Privada & 1959 & 24.769 & $\begin{array}{c}\text { Não acreditada } \\
\text { (Desenvolvendo }\end{array}$ & PR \\
\hline
\end{tabular}




\begin{tabular}{|c|c|c|c|c|c|c|}
\hline & $\begin{array}{l}\text { continuada (150 cursos). } \\
\text { Pós-graduação stricto sensu } \\
\text { (16 programas). }\end{array}$ & & & & o processo) & \\
\hline D & $\begin{array}{c}\text { Graduação em diversas áreas } \\
\text { (84 cursos) e diversos cursos } \\
\text { de pós-graduação lato e } \\
\text { stricto sensu. }\end{array}$ & Pública & 1934 & 27.768 & $\begin{array}{l}\text { Não acreditada } \\
\text { (Iniciando o } \\
\text { processo) }\end{array}$ & $\mathrm{RS}$ \\
\hline $\mathrm{E}$ & $\begin{array}{c}\text { Possui } 87 \text { de graduação em } \\
\text { diversas áreas e diversos } \\
\text { cursos de pós-graduação lato } \\
\text { e stricto sensu. }\end{array}$ & Privada & 1969 & 31.000 & $\begin{array}{l}\text { Não acreditada } \\
\text { (Desenvolvendo } \\
\text { o processo) }\end{array}$ & $\mathrm{RS}$ \\
\hline
\end{tabular}

Fonte: Elaborada pelos autores.

A coleta dos dados foi feita por intermédio de entrevistas estruturadas, guiadas por um roteiro com uma lista de perguntas, pois procurou-se entender o fenômeno investigado com profundidade. Este roteiro foi pré-testado e dividido em duas etapas: estratégia de acreditação e institucionalização da acreditação internacional. As 15 entrevistas foram realizadas junto a 4 Decanos (diretores), 6 coordenadores de cursos de gestão e negócios, 2 docentes, 1 gerente administrativo, 2 analistas responsáveis pelo projeto de acreditação ou pelo setor de avaliação institucional, todos envolvidos com o processo de acreditação nas IES investigadas. As entrevistas foram feitas pessoalmente e por Skype. O tempo médio de duração de cada entrevista foi de 1 hora e 30 minutos. A sua transcrição totalizou 188 páginas e está contida no Relatório de Entrevistas e totaliza 188 páginas. Também foram coletados dados secundários nos sítios eletrônicos das cinco EGN.

As entrevistas foram codificadas segundo categorias de análise formuladas em consonância com a teoria, os construtos e o instrumento de pesquisa. A análise dos dados contou com auxílio do software NVivo Pro®, versão 11 e adotou a análise de conteúdo e análises descritivas de frequências como métodos de análise.

\section{ANÁLISE E DISCUSSÃO DOS RESULTADOS}

\subsection{ANÁLISE DAS ENTREVISTAS POR FREQUÊNCIA DE PALAVRAS}

Para obter uma noção preliminar do conteúdo abrangido nas entrevistas, foram elaboradas nuvens de palavras, para ilustrar a frequência dos dados linguísticos inclusos no texto, facilitando a identificação de palavras significativas. Para fins de comparação entre as percepções dos envolvidos com o processo de institucionalização da acreditação internacional 
nas EGN investigadas, foram criadas duas categorias de nuvens: 1) nuvens de palavras dos decanos; 2) nuvem de palavras dos demais entrevistados.

Figura 3 Nuvens de Palavras

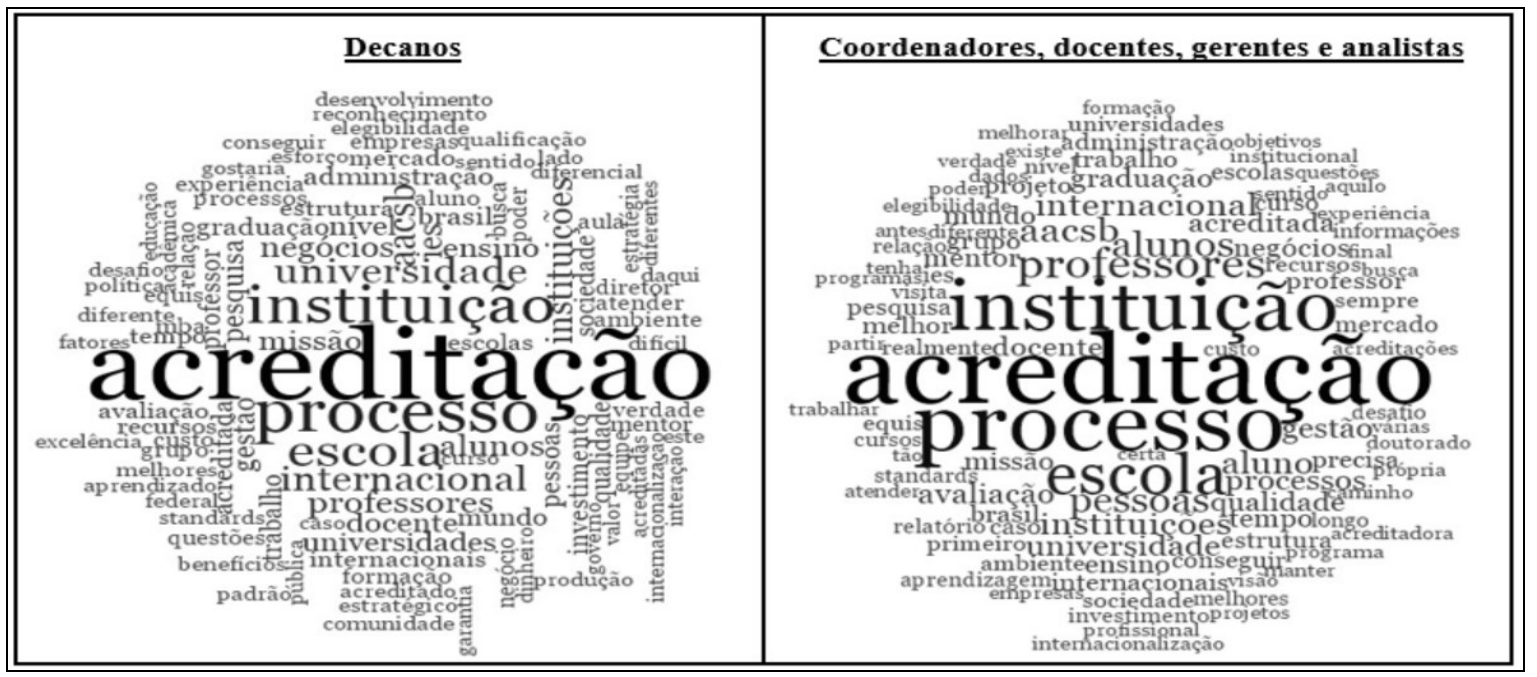

Fonte: Elaborada pelos autores.

A primeira nuvem de palavras permite perceber que, a partir da narrativa dos Decanos entrevistados, surgem mais frequentemente as palavras: instituição, acreditação, processo, escola e internacional. Assim, pode-se presumir que essa elevada frequência decorre do cenário em que acontece o processo de institucionalização da acreditação e do envolvimento dos entrevistados com o assunto da pesquisa. Porém, as demais palavras que se destacaram podem também apontar outros assuntos abrangidos no contexto, como, por exemplo, professores, negócios, desenvolvimento, reconhecimento e elegibilidade. Em relação à segunda nuvem, da Figura 3, observa-se que, no relato dos entrevistados desta categoria (coordenadores, gerentes, docentes e analistas), o uso mais frequente das palavras foi: instituição, acreditação, processo, escola, professores, alunos, pessoas, universidade, internacional e AACSB. Percebe-se as palavras "instituição", "acreditação" e "processo" foram as que mais se destacaram nos dois grupos. Esta situação é vista como positiva, pois denota a possibilidade de captar impressões semelhantes ainda que com categorias de entrevistados distintas.

Contudo, quando é realizada a comparação entre as duas nuvens de palavras, constatam-se dissemelhanças no restante das frequências das palavras, e as palavras mais expressivas são, relativamente, diferentes entre as duas categorias de pessoas. Esses resultados sinalizam que, possivelmente, há percepções diferentes sobre a institucionalização 
e os desafios da implantação da acreditação internacional, entre os decanos e os coordenadores, gerente, docentes e analistas das IES investigadas.

\subsection{FATORES DETERMINANTES DA ESTRATÉGIA DE ACREDITAÇÃO INTERNACIONAL}

O estudo contemplou cinco EGN de grande porte, sendo 4 privadas e 1 pública, das quais três estão situadas na região Sul, e duas na região Sudoeste do Brasil. Os fatores determinantes da acreditação institucional para estas EGN, em termos das estratégias e da decisão para implantar a acreditação internacional figuram no Quadro 2.

Quadro 2 Fatores determinantes da Acreditação Internacional

\begin{tabular}{|c|c|c|}
\hline EGN & Situação & Fatores determinantes \\
\hline A & Acreditada & $\begin{array}{l}\text { "[...] a AACSB procurava expandir a sua própria internacionalização, } \\
\text { então ela passou a convidar, a divulgar o processo, e a escola foi } \\
\text { convidada a participar desse processo. Então, no início, teve esse outro } \\
\text { componente, quer dizer, além, talvez da questão estratégica, [...] no ano } \\
\text { 2000, a AACSB estava em processo de internacionalização e procurou } \\
\text { divulgar na comunidade internacional o que é uma acreditação e convidar } \\
\text { as escolas a participarem desse processo." }\end{array}$ \\
\hline B & Acreditada & $\begin{array}{l}\text { "Então, acreditação internacional não é um diferencial para você } \\
\text { conseguir melhores alunos aqui, mas é a uma condição fundamental para } \\
\text { que você consiga se internacionalizar." [...] "Claro que a gente quer } \\
\text { também o selo, resultado e reconhecimento, mas o processo de } \\
\text { desenvolvimento é pra gente estrategicamente mais importante." [...] "Há } \\
\text { um ponto importante, por exemplo, para estabelecimentos de acordos de } \\
\text { dupla titulação...” [...] “A implantação começou, de fato, em 2004, a } \\
\text { partir de uma visão de acreditação para ter benchmarking } \\
\text { internacional." }\end{array}$ \\
\hline $\mathrm{C}$ & $\begin{array}{c}\text { Membro } \\
\text { desenvolvend } \\
\text { o o processo } \\
\text { de acreditação }\end{array}$ & $\begin{array}{l}\text { "Vários fatores, o principal é o nosso posicionamento estratégico de } \\
\text { sermos uma escola de negócios de excelência e internacionalizada. Em } \\
\text { função desse alinhamento do planejamento estratégico da universidade, } \\
\text { que tem também como foco a busca da internacionalização, a acreditação } \\
\text { internacional veio como uma ação estratégica para viabilizar essa } \\
\text { internacionalização, e também para conquistar uma posição de } \\
\text { excelência e referencia nacional com influencia internacional, e a partir da } \\
\text { acreditação também facilita muito a interaçãa entre universidades e } \\
\text { escolas de negócios de nível... de primeiro nível... sem a acreditação, } \\
\text { dificilmente a gente tem espaço para desenvolver projetos e ter parcerias } \\
\text { de escolas de primeiro nível." }\end{array}$ \\
\hline D & $\begin{array}{l}\text { Membro em } \\
\text { processo } \\
\text { tomada de } \\
\text { decisão para } \\
\text { iniciar a } \\
\text { acreditação }\end{array}$ & $\begin{array}{l}\text { “A acreditação é um processo praticamente inevitável, nós recebemos } \\
\text { parceiros internacionais que começaram a pedir a acreditação. A } \\
\text { acreditação serve como um moderador, um facilitador, na verdade de } \\
\text { interações entre as instituições, [...] as duplas titulações, enviar } \\
\text { estudantes para cá para ter o curso reconhecido internacionalmente, tudo } \\
\text { isso cria quase como se fosse uma comunidade integrada, de } \\
\text { universidades que se reconhecem mutuamente como competentes." }\end{array}$ \\
\hline
\end{tabular}




\begin{tabular}{|c|c|c|c|}
\hline \multirow{4}{*}{ E } & $\begin{array}{c}\text { Membro } \\
\text { desenvolvend } \\
\text { o o processo } \\
\text { de acreditação }\end{array}$ & $\begin{array}{c}\text { "Quando uma instituição busca uma acreditação independente, busca para } \\
\text { melhorar os seus cursos, para melhorar os seus processos, para encontrar } \\
\text { parâmetros externos de comparação. Esse é o grande motivador." [...] "Ela } \\
\text { tem um motivador de qualificar um trabalho que é desenvolvido." [...] } \\
\text { "ser acreditado por uma instituição reputada e externa é quase que uma } \\
\text { condição para o relacionamento internacional." }\end{array}$ \\
\hline
\end{tabular}

Fonte: Elaborado pelos autores.

$\mathrm{Na}$ análise acima, percebe-se que, quase por unanimidade, as EGN investigadas citaram os mesmos fatores determinantes para buscar a acreditação internacional, ou seja, pode-se constatar que os fatores mais relatados pelos entrevistados das EGN foram: "internacionalização", “estratégia", "dupla titulação", "reconhecimento", “interações internacionais", "parcerias internacionais" e "busca de melhoria dos processos". Outros fatores também citados, porém, com menos veemência foram: "benchmarking internacional", qualificação da instituição e "convite da acreditadora". Tais aspectos assemelham-se, em parte, aos conferidos por outros processos de avaliação institucional (como, por exemplo, a do Ministério da Educação - MEC, promovida pela Coordenação de Aperfeiçoamento de Pessoal de Nível Superior - CAPES). Entretanto, a avaliação do MEC/CAPES vale para IES de todas as áreas do conhecimento e parte de um padrão único, com regras, parâmetros e níveis predefinidos. Já a acreditação internacional específica para EGN, que também é baseada em regras e normas definidas pela acreditadora, configura um padrão mais adaptável às prioridades estratégicas e aos princípios de ensino e aprendizagem das EGN.

Observa-se, ainda, que há convergência entre as EGN em relação aos seguintes elementos: "internacionalização" e "reconhecimento", presente em todas; "dupla titulação", presente nas EGN B e D; "relacionamento", "interação" e "parceria" entre as instituições, presente nas EGN B, C, D e E; "ação estratégica", presente nas EGN A e C; "melhoria de processos", presente nas EGN A e E.

A partir desses achados, respondendo às proposições da pesquisa (P1, P2 e P3), podese afirmar que os fatores determinantes para a busca da acreditação pelas EGN investigadas, resultaram com maior número de observações de pressões isomórficas coercitivas (internacionalização, reconhecimento, parcerias internacionais) e miméticas (dupla titulação, interações internacionais e busca da melhoria dos processos) e, com menor número de observações de pressões normativas (benchmarking internacional e qualificação da instituição). Estes resultados corroboram com os achados de Istileulova e Peljhan (2015), que apontaram que nas EGN da Lituânia, as parcerias internacionais e o reconhecimento 


\section{A INSTITUCIONALIZAÇÃO DA ACREDITAÇÃO INTERNACIONAL EM ESCOLAS DE GESTÃO E NEGÓCIOS BRASILEIRAS: FATORES DETERMINANTES, PERSPECTIVAS E DESAFIOS DOI: http://dx.doi.org/10.5007/1983-4535.2018v11n2p222}

internacional para atrair mais estudantes foram às razões mais citadas pelas EGN para a tomada de decisão de institucionalizar a acreditação internacional. Estes achados também ratificam os resultados de Cooper, Parkes e Blewitt (2014) que encontraram que a institucionalização é um dos fatores que determinam a busca pelas acreditações internacionais das EGN.

No tocante às perspectivas, benefícios e resultados que são esperados pela EGN com a institucionalização da acreditação internacional, os entrevistados relataram o que foi resumido no Quadro 3, no qual foram diferenciadas as percepções dos decanos em relação aos demais envolvidos no processo de acreditação.

Quadro 3 Perspectivas, benefícios e resultados esperados pelas EGN

\begin{tabular}{|c|c|}
\hline Na visão dos Decanos & $\begin{array}{l}\text { Na visão dos coordenadores, docentes e } \\
\text { analistas }\end{array}$ \\
\hline $\begin{array}{l}\text { Estruturar todos os processos da instituição, } \\
\text { garantir o aprendizado, trabalhar os currículos } \\
\text { para melhorar os resultados, } \\
\text { internacionalização, manter-se conectado no } \\
\text { ambiente internacional. }\end{array}$ & $\begin{array}{l}\text { Melhorar a padronização de qualidade dos } \\
\text { processos internos, adequar aos padrões } \\
\text { internacionais, aumentar a quantidade de } \\
\text { alunos de intercâmbio, parcerias } \\
\text { internacionais, duplo diploma. }\end{array}$ \\
\hline $\begin{array}{l}\text { Internacionalização da EGN, fazer parcerias } \\
\text { com escolas de alto nível, ter um padrão } \\
\text { internacional como referência para os alunos } \\
\text { e para fortalecer ainda mais o nosso } \\
\text { posicionamento de qualidade no mercado } \\
\text { nacional. }\end{array}$ & $\begin{array}{l}\text { Ser reconhecido no mercado, ter uma imagem } \\
\text { mais positiva na sociedade, aprimorar os } \\
\text { processos institucionais, para alcance da missão } \\
\text { estabelecida pela instituição, estimular a melhora } \\
\text { da comunicação interna, da missão e dos objetivos } \\
\text { estratégicos. }\end{array}$ \\
\hline Qualificar um trabalho que já é desenvolvido. & $\begin{array}{l}\text { Entregar a qualidade proposta para o ensino, } \\
\text { internacionalização, firmar convênios para as } \\
\text { pesquisas, e valorizar o planejamento estratégico. }\end{array}$ \\
\hline $\begin{array}{l}\text { Ter um padrão de ensino compatível com os } \\
\text { padrões internacionais, governança interna } \\
\text { mais estruturada, possibilidade de usar outras } \\
\text { instituições como referência, melhorar a } \\
\text { gestão, internacionalização, acesso a fundos } \\
\text { de investimentos internacionais. }\end{array}$ & $\begin{array}{l}\text { Buscar e enviar alunos para escolas estrangeiras, } \\
\text { melhorar a gestão da aprendizagem, processos } \\
\text { mais transparentes, obter reconhecimento dos } \\
\text { alunos, agregar valor para a sociedade, ter } \\
\text { benefícios econômicos, alunos mais qualificados, } \\
\text { maior demanda, qualificar docentes, visar } \\
\text { melhores práticas. }\end{array}$ \\
\hline
\end{tabular}

Fonte: Elaborado pelos autores.

A análise das respostas revela que tanto os decanos quanto os coordenadores, docentes, gerentes e analistas esperam que, com a institucionalização da acreditação, eles poderão viabilizar a internacionalização e conseguir a adequação das EGN aos padrões internacionais. Aparentemente, as perspectivas dos coordenadores, docentes, gerentes e analistas são mais abrangentes. Este grupo espera, que com institucionalização da acreditação internacional, sejam obtidos benefícios tanto internos quanto externos, como, por exemplo, a 


\section{A INSTITUCIONALIZAÇÃO DA ACREDITAÇÃO INTERNACIONAL EM ESCOLAS DE GESTÃO E NEGÓCIOS BRASILEIRAS: FATORES DETERMINANTES, PERSPECTIVAS E DESAFIOS DOI: http://dx.doi.org/10.5007/1983-4535.2018v11n2p222}

melhoria da padronização dos processos internos, a qualificação do corpo docente, benefícios econômicos, parcerias internacionais, dupla diplomação e intercâmbios. Estes achados têm semelhança com os resultados de Roller, Andrews e Bovee (2010), cujos benefícios mais significativos da implantação da acreditação foram: reconhecimento como uma instituição superior; e, oportunidades para compartilhar técnicas, sucessos e desafios com outras instituições que enfrentam problemas semelhantes.

Em relação à estratégia, perguntou-se aos entrevistados qual o diferencial para o aluno em estudar em uma EGN acreditada internacionalmente. Com a ajuda da estatística descritiva de frequência, elaborou-se um ranking que evidencia em ordem decrescente os diferenciais que foram apontados pelos representantes das EGN brasileiras, na Tabela 1.

Tabela 1 Diferenciais da acreditação internacional para os alunos na percepção dos entrevistados

\begin{tabular}{c|l|c|c}
\hline Item & \multicolumn{1}{|c|}{ Diferenciais percebidos } & $\mathbf{N}^{\circ}$ de observações & $\mathbf{\%}$ \\
\hline 1 & Oportunidade no Mercado para Carreira Internacional & 9 & 20,93 \\
2 & Oportunidade de Intercâmbio na Graduação & 7 & 16,28 \\
3 & Garantia da Aprendizagem & 6 & 13,95 \\
4 & Reconhecimento de Qualidade Diferenciada Internacional & 5 & 11,63 \\
5 & Currículo de Qualidade & 5 & 11,63 \\
6 & Oportunidade de Pós-graduação Sanduíche fora do País & 4 & 9,30 \\
7 & Diploma Reconhecido Internacionalmente & 4 & 9,30 \\
8 & Agregar Valor à Sociedade & 2 & 4,65 \\
9 & Facilidade de obter Bolsas de Estudos & 1 & 2,33 \\
\hline \multicolumn{2}{r}{ Total } & $\mathbf{4 3}$ & $\mathbf{1 0 0 , 0 0}$ \\
\hline
\end{tabular}

Fonte: Elaborada pelos autores.

De acordo com a Tabela 1, os diferenciais para o aluno em estudar em uma EGN acreditada internacionalmente são: oportunidade no mercado internacional; oportunidade de intercâmbio; garantia da aprendizagem; reconhecimento de qualidade diferenciada internacionalmente; currículo de qualidade; oportunidade de pós-graduação sanduíche; diploma reconhecido internacionalmente; agregar valor à sociedade; e, facilidade de obter bolsas de estudos. Porém, os diferenciais mais destacados, conforme os entrevistados, foram: oportunidade no mercado para carreira internacional $(20,93 \%)$, a oportunidade de fazer intercâmbio na graduação (16,28\%), e garantia da aprendizagem (13,95\%). Diferenciais, tais como, reconhecimento de qualidade diferenciada internacionalmente e currículo de qualidade, receberam o mesmo número de observações $(11,63 \%)$.

$\mathrm{Na}$ oportunidade, os entrevistados também foram questionados sobre o diferencial para a EGN em possuir acreditação internacional. O resultado é ilustrado na Tabela 2. 
Tabela 2 Diferenciais da Acreditação Internacional para as EGN na percepção dos entrevistados

\begin{tabular}{c|c|c|c}
\hline Item & Diferencial percebidos & $\begin{array}{c}\mathbf{N}^{\circ} \mathbf{d e} \\
\text { observações }\end{array}$ & $\mathbf{\%}$ \\
\hline 1 & Selo de Alta Qualidade & 9 & 21,43 \\
2 & Reconhecimento no Mercado & 7 & 16,67 \\
3 & Internacionalização & 4 & 9,52 \\
4 & Programas de Intercâmbio & 3 & 7,14 \\
5 & Melhoria Contínua e Boas Práticas na IES & 3 & 7,14 \\
6 & Qualidade na Aprendizagem & 3 & 7,14 \\
7 & Padrão Internacional & 3 & 7,14 \\
8 & Parcerias Internacionais & 3 & 7,14 \\
9 & Qualidade do Corpo Docente & 2 & 4,76 \\
10 ao 14 & Benchmarking; Legitimidade; Cultura Internacional; & 1 (cada) & 2,38 \\
& Inovação; Agregar Valor aos Discentes & (cada) \\
\hline \multicolumn{4}{c}{ Total } \\
\hline
\end{tabular}

Fonte: Elaborado pelos autores.

Observa-se, na Tabela 2, que na percepção dos entrevistados, o maior diferencial das EGN por ser acreditada internacionalmente é o selo de alta qualidade $(21,43 \%)$, seguido pelo reconhecimento no mercado $(16,67 \%)$, que também obteve uma votação expressiva. Isso evidencia que, para as IES estudadas, ser reconhecido pelo mercado é um fator impactante em termos de estratégia competitiva para implantar a acreditação internacional.

\subsection{OS DESAFIOS NO PROCESSO DE INSTITUCIONALIZAÇÃO DA ACREDITAÇÃO INTERNACIONAL}

Para demonstrar quais foram os desafios encontrados no processo de institucionalização da acreditação, foi elaborada a Figura 4, que está estruturada com base nas três etapas (habitualização, objetificação e sedimentação) teorizadas por Tolbert e Zucker (1999). Essa representação visa facilitar a compreensão e o entendimento da associação dos desafios com os momentos institucionais que são enfrentados para obter a acreditação internacional. 


\section{A INSTITUCIONALIZAÇÃO DA ACREDITAÇÃO INTERNACIONAL EM ESCOLAS DE GESTÃO E NEGÓCIOS BRASILEIRAS: FATORES DETERMINANTES, PERSPECTIVAS E DESAFIOS DOI: http://dx.doi.org/10.5007/1983-4535.2018v11n2p222}

Figura 4 Os Desafios no Processo de Institucionalização

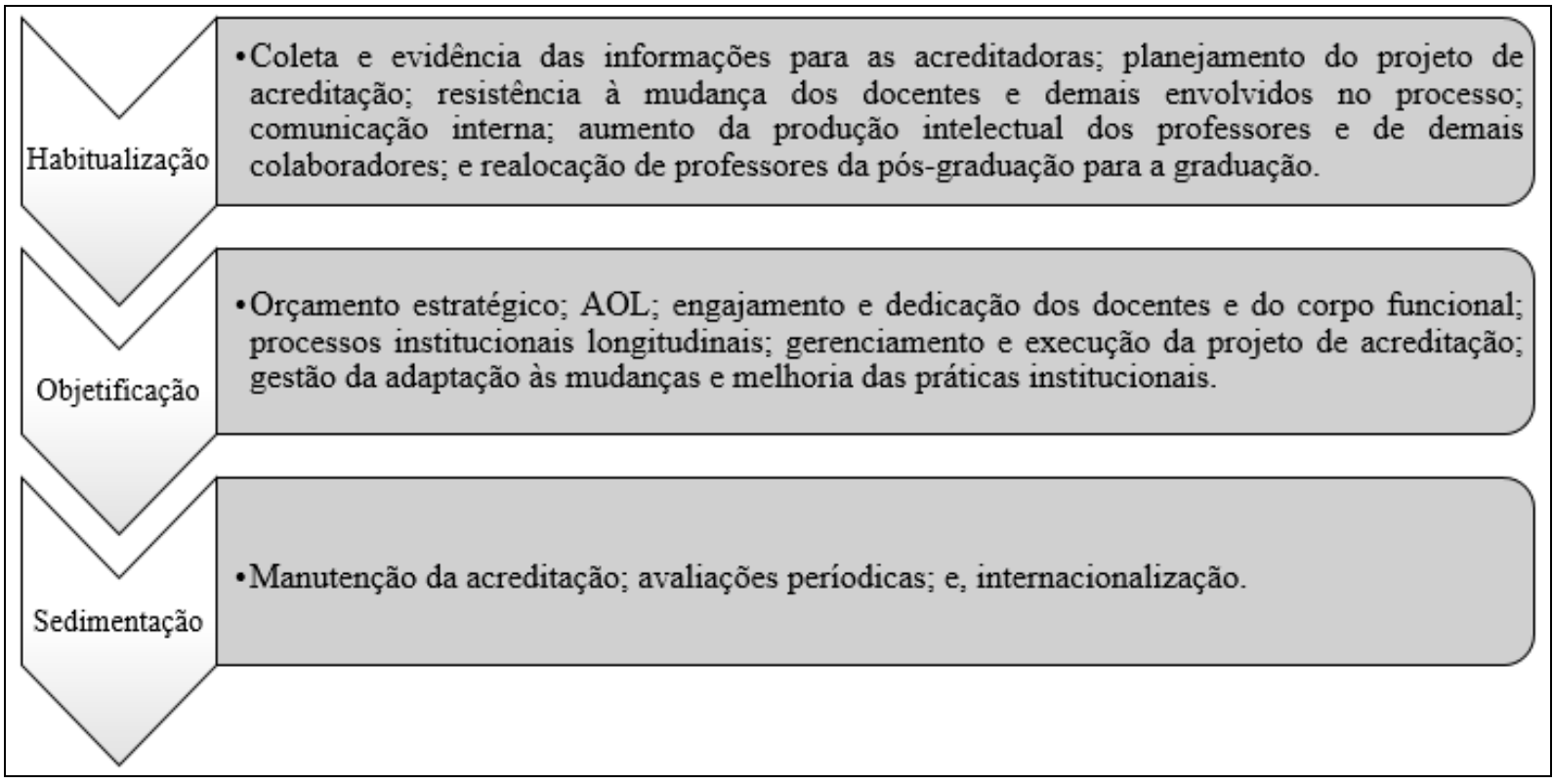

Fonte: Elaborada pelos autores.

De acordo com os entrevistados, o maior nível de desafio é enfrentado na etapa de habitualização, pois é nesta fase que ocorre a maior quantidade de fatores considerados críticos no processo de acreditação em termos de esforço, custo ou complexidade. De acordo com a Figura 4, é na etapa de habitualização que ocorre a coleta e evidência das informações a serem apresentadas para acreditadora, a fim de comprovar os requisitos de elegibilidade junto a ela. Para os entrevistados, a coleta e a evidenciação de informações não são uma tarefa simples, pois as informações precisam, antecipadamente, ser estudadas, tratadas e analisadas antes da entrega final. A instituição deve reportar informações sobre seu quadro docente (identificação, qualificação, produção científica e atividade profissional) e sobre sua declaração estratégica (proposta de valor, missão, visão, valores e princípios que movem a atividade institucional), assim como sobre seus processos internos de gestão e execução das atividades de ensino.

Então, para que o processo ocorra de forma organizada, geralmente é estruturado o planejamento do projeto de acreditação, com uma equipe focal multidisciplinar. São realizadas reuniões na própria instituição para delegar as responsabilidades dos participantes no processo da acreditação, e também avaliar todo o conteúdo apurado na coleta que deve ser entregue para a acreditadora. É na etapa de habitualização, conforme os entrevistados, que são enfrentadas as mais intensas resistências às mudanças, tanto da parte dos docentes quanto dos 


\section{A INSTITUCIONALIZAÇÃO DA ACREDITAÇÃO INTERNACIONAL EM ESCOLAS DE GESTÃO E NEGÓCIOS BRASILEIRAS: FATORES DETERMINANTES, PERSPECTIVAS E DESAFIOS DOI: http://dx.doi.org/10.5007/1983-4535.2018v11n2p222}

demais envolvidos no processo. É preciso uma comunicação adequada e sustentada por parte dos decanos das EGN para convencer tanto a alta administração das IES (reitoria, direção das escolas) quanto a parte produtiva (professores) que "acreditar é preciso e que o momento é agora". Colby (2016) enfatiza a importância do compromisso do pessoal envolvido para apoiar e aderir ao método para que o sistema implementado de modo mais eficiente. Nesta etapa, ocorrem ainda os ajustes considerados "críticos", como o aumento da produção intelectual e desenvolvimento profissional dos docentes e dos demais envolvidos no processo, como, por exemplo, a exigência para que os demais colaboradores envolvidos no processo também aprendam outras línguas, e a realocação e equalização do quadro de professores entre pós-graduação e graduação, pois, conforme os entrevistados, a instituição precisa ter um equilíbrio de professores qualificados na graduação e na pós-graduação. Esses resultados se assemelham com os achados de Miles et al (2014).

$\mathrm{Na}$ etapa objetificação são enfrentados outros tipos de desafios, como a execução do orçamento estratégico. Segundo os entrevistados, nesta etapa percebe-se que os custos para adquirir a acreditação não se limitam apenas à anuidade paga à acreditadora, mas, dependendo de cada caso, contemplam até mesmo as modificações da estrutura da organização, como, por exemplo, adequação de instalações físicas, investimentos em tecnologias, reconfiguração de processos, criação de estrutura organizacional ou de comitê específico para gestão da acreditação, além dos investimentos em cursos de qualificação para todos os colaboradores da EGN. Logo, é preciso elaborar o orçamento estratégico levantando-se e mensurando-se todos os pontos necessários para a implantação das iniciativas previstas no plano de ação de acreditação, para que se possa ter a dimensão dos custos e benefícios que serão adquiridos com a institucionalização deste processo.

Na objetificação, foi evidenciado um dos desafios mais citados pelos entrevistados: AOL (Assurance Of Learning), isto é, a garantia da aprendizagem. O desafio de encontrar evidências de avaliação e mensuração que dê a garantia da aprendizagem do aluno, tem se tornado uma das tarefas mais difíceis de ser enfrentada e superada para as EGN brasileiras. Porém, apesar de crítica, a AOL foi considerada pelos entrevistados como uma ferramenta de suma importância para definir a proposta de valor e medir e avaliar a missão fundamental da instituição de ensino: a aprendizagem.

Foi enfatizado pelos entrevistados que, para enfrentar e superar os desafios, é preciso ter o total engajamento e dedicação do corpo docente e do corpo funcional, pois os processos 


\section{A INSTITUCIONALIZAÇÃO DA ACREDITAÇÃO INTERNACIONAL EM ESCOLAS DE GESTÃO E \\ NEGÓCIOS BRASILEIRAS: FATORES DETERMINANTES, PERSPECTIVAS E DESAFIOS \\ DOI: http://dx.doi.org/10.5007/1983-4535.2018v11n2p222}

de acreditação são considerados intensos e longitudinais, pois o ciclo de cada um, geralmente, leva cerca de 2 a 6 anos para ser concluído. É na etapa de objetificação que ocorre o gerenciamento e a execução do projeto de acreditação, a adaptação às mudanças trazidas pelo processo de acreditação, e o desenvolvimento de melhorias e aperfeiçoamentos nas práticas institucionais. Tais achados estão coerentes com os resultados encontrados por Miles et al (2014), Colby, Lambert e McGee (2016) e Hasbun e Rudolph (2016). Com a consagração da acreditação internacional, novos desafios são vislumbrados na fase de sedimentação da institucionalização.

Em relação à etapa de sedimentação, de acordo com os entrevistados, pode-se citar, primeiramente, o desafio de manutenção da acreditação, mencionado pela maioria dos decanos como sendo um fator extremamente crítico no processo de institucionalização. De acordo com os entrevistados, investir na melhoria contínua, manter a equipe de acreditação, sustentar o orçamento anual da acreditação e assegurar a continuidade e o alinhamento estratégico em eventuais mudanças da composição da alta administração (reitoria e diretorias) são desafios característicos desta etapa. Ademais, as avaliações periódicas e a renovação das acreditações também foram citadas como um desafio crítico da sedimentação da institucionalização, pois não ocorrem automaticamente após a obtenção da acreditação inicial, uma vez que dependem da continuidade dos esforços e investimentos da instituição e da interação com as demais instituições já acreditadas. A seguir, exibe-se a Figura 5, a fim de mapear em quais etapas de institucionalização estão localizadas as EGN estudadas.

Figura 5 Institucionalização da Acreditação nas EGN Brasileiras

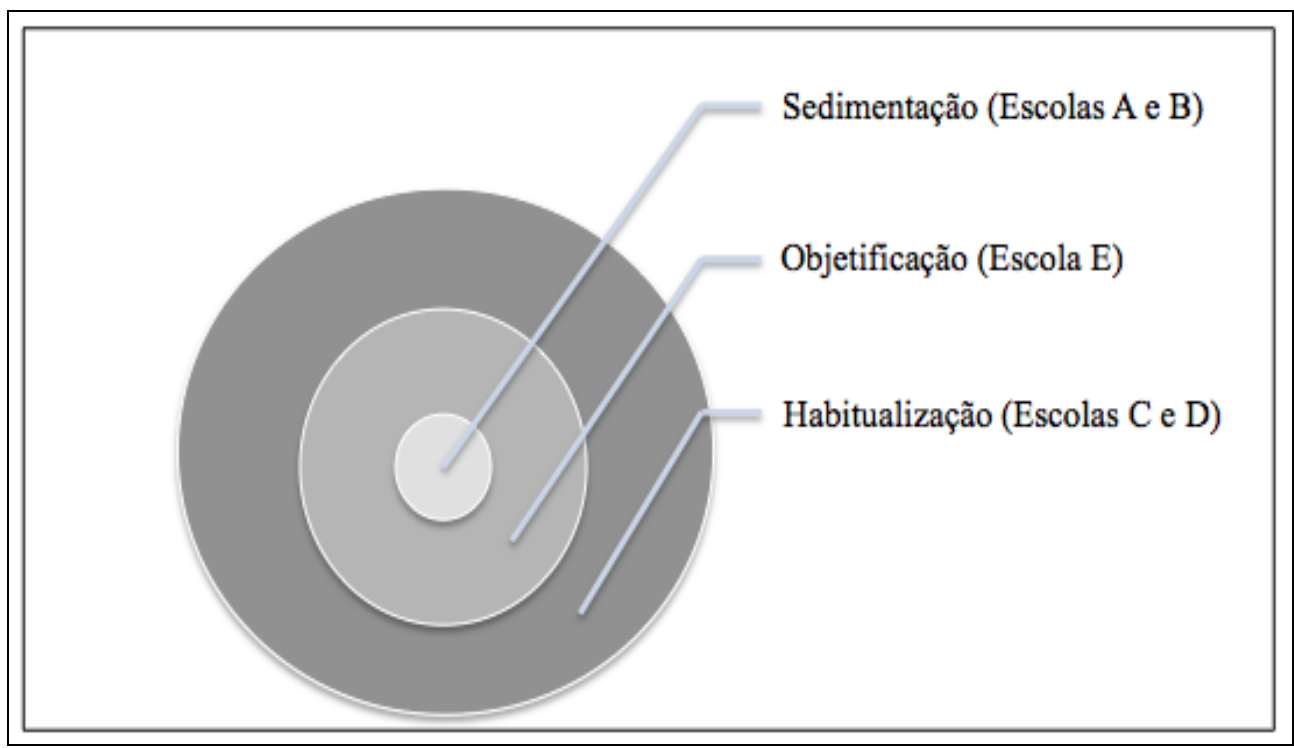

Fonte: Elaborada pelos autores. 


\section{A INSTITUCIONALIZAÇÃO DA ACREDITAÇÃO INTERNACIONAL EM ESCOLAS DE GESTÃO E \\ NEGÓCIOS BRASILEIRAS: FATORES DETERMINANTES, PERSPECTIVAS E DESAFIOS \\ DOI: http://dx.doi.org/10.5007/1983-4535.2018v11n2p222}

Esse mapeamento foi realizado com base nas respostas dos entrevistados e nas informações obtidas pelo sítio das instituições pesquisadas. Com base nestes dados foi possível identificar em qual etapa do processo de institucionalização se encontrava cada uma das EGN investigadas no momento da realização da pesquisa. Portanto, respondendo a última preposição da pesquisa (P4), pode-se afirmar que a institucionalização de acreditações internacionais possui diversos desafios e transcorre nas três etapas (habitualização, objetificação e sedimentação) do modelo de Tolbert e Zucker (1999).

\section{CONSIDERAÇÕES FINAIS}

Este estudo investigou como ocorrem os processos de adoção e a implementação da estratégia de acreditação internacional em EGN brasileiras. A lente teórica, adotada para a explicação do fenômeno, foi a Teoria Institucional, especificamente em relação às pressões isomórficas institucionais e ao processo de institucionalização de mudanças estratégicas. $\mathrm{O}$ objetivo foi analisar os fatores determinantes, desafios e perspectivas da institucionalização da acreditação internacional nas escolas de gestão e negócios das instituições de ensino superior no Brasil. Foram entrevistadas 15 integrantes de cinco EGN, das quais uma está em fase de tomada de decisão para iniciar o processo de acreditação, duas estão desenvolvendo seu processo de acreditação e duas já acreditadas internacionalmente pela AACSB.

Confirmaram-se as proposições de pesquisa, ao evidenciar-se que as pressões isomórficas estão presentes nas razões que motivam a decisão de implementar o processo de acreditação; as pressões coercitivas e miméticas, com um maior número de observações, e as pressões normativas, com um menor número de observações, dentre os achados evidenciados a partir dos fatores determinantes da formulação e da adoção da estratégia de acreditação internacional. Além disso, constatou-se que a institucionalização de acreditações internacionais transcorre por meio das etapas de habitualização, no momento de preparação da EGN para requerer sua elegibilidade junto à acreditadora, de objetificação, durante a execução dos planos de ação para implementação dos requisitos e adequações para consagrarse acreditada e, após a acreditação, da etapa de sedimentação, ao prosseguir com as melhorias continuas, a fim de sustentar e renovar a acreditação internacional. Em todas essas etapas foram destacados os desafios mais críticos na visão dos agentes envolvidos.

A presente pesquisa limitou-se a estudar os processos de acreditação de EGN pela AACSB, uma das principais acreditadoras internacionais. A partir deste estudo, emergem 


\section{A INSTITUCIONALIZAÇÃO DA ACREDITAÇÃO INTERNACIONAL EM ESCOLAS DE GESTÃO E NEGÓCIOS BRASILEIRAS: FATORES DETERMINANTES, PERSPECTIVAS E DESAFIOS DOI: http://dx.doi.org/10.5007/1983-4535.2018v11n2p222}

oportunidades de pesquisas futuras, que podem, por exemplo, aprofundar a compreensão dos fatores determinantes, em especial as pressões isomórficas, bem como dedicar-se a identificar as melhores práticas para enfrentamento dos desafios para gestão das mudanças que envolvem a qualificação da estratégia, dos processos, serviços, e da própria imagem institucional.

Por fim, espera-se, com este estudo, contribuir para a ampliação do conhecimento e qualificação das práticas de gestão estratégica nas EGN, auxiliando na difusão dessa importante estratégia de acreditação, capaz de estimular e beneficiar diversas dimensões da gestão de uma IES. Essas contribuições abrangem a reestruturação estratégica e evidenciação dos resultados das proposições de valor das instituições para a sociedade, a reorganização e padronização dos processos e qualificação organizacional, de acordo com boas práticas internacionais. Tais afirmações confirmam os achados dos estudos de Miles et al (2014), Colby, Lambert e McGee (2016) e Hasbun e Rudolph (2016), principalmente nas questões sobre a necessidade do reposicionamento da estratégia, na interação e engajamento dos profissionais envolvidos no processo de aprendizagem e no desenvolvimento de melhorias durante a institucionalização da acreditação. Portanto, a acreditação internacional contempla uma mudança estratégica de paradigma que beneficia as EGN com o reconhecimento internacional e o envolvimento em uma rede de parceria com outras EGN acreditadas, favorecendo a internacionalização e a qualificação do quadro docente e técnico, e propiciando melhoria na aprendizagem dos alunos. Com isso, tanto alunos como docentes podem acessar mais oportunidades qualificadas de ensino e aprendizagem no mercado internacional.

\section{REFERÊNCIAS}

ACKOFF, R. L. Planejamento Empresarial. Rio de Janeiro, 1983.

ALÁSTICO, Gabriel P. Impactos das práticas da acreditação no desempenho hospitalar: Um survey em hospitais do estado de São Paulo. Tese (Doutorado) - Universidade Federal de São Carlos, Centro de Ciências Exatas e de Tecnologia, São Paulo, 2013.

ANTUNES, Don; THOMAS, Howard. The competitive (dis) advantages of European business schools. Long Range Planning, v. 40, n. 3, p. 382-404, 2007.

ASHWORTH, Rachel; BOYNE, George; DELBRIDGE, Rick. Escape from the iron cage? Organizational change and isomorphic pressures in the public sector. Journal of Public Administration Research and Theory, v. 19, n. 1, p. 165-187, 2009.

ASSOCIATION TO ADVANCE COLLEGIATE SCHOOLS OF BUSINESS (AACSB).

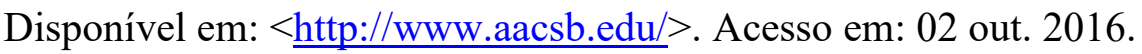


ASSOCIATION TO ADVANCE COLLEGIATE SCHOOLS OF BUSINESS (AACSB). Eligibility procedures and accreditation standards for business accreditation. 2013.

BAILEY, Allan R.; CHOW, Chee W.; HADDAD, Kamal M. Continuous improvement in business education: Insights from the for-profit sector and business school deans. Journal of Education for Business, v. 74, n. 3, p. 165-180, 1999.

BELL, Stephen. Do we really need a new 'constructivist institutionalism' to explain institutional change? British Journal of Political Science, v. 41, n. 4, p. 883-906, 2011. COLBY, Susan; LAMBERT, Monica; MCGEE, Jennifer. Utilizing Collaborative Analysis of Student Learning in Educator Preparation Programs for Continuous Improvement. SAGE Open, v. 6, n. 4, p. 2158244016673131, 2016.

COOPER, Stuart; PARKES, Carole; BLEWITT, John. Can accreditation help a leopard change its spots? Social accountability and stakeholder engagement in business schools. Accounting, Auditing \& Accountability Journal, v. 27, n. 2, p. 234-258, 2014.

CRUBELLATE, João Marcelo; GRAVE, Paulo Sérgio; MENDES, Ariston Azevedo. A questão institucional e suas implicações para o pensamento estratégico. Revista de Administração Contemporânea, p. 37, 2004.

DIMAGGIO, Paul J. (Ed.). The new institutionalism in organizational analysis. Chicago, IL: University of Chicago Press, 1991.

DIMAGGIO, Paul J.; POWELL, Walter W. A gaiola de ferro revisitada: isomorfismo institucional e racionalidade coletiva nos campos organizacionais. RAE-Revista de Administração de Empresas, v. 45, n. 2, p. 74-89, 2005.

FRIGA, Paul N.; BETTIS, Richard A.; SULLIVAN, Robert S. Changes in graduate management education and new business school strategies for the 21 st century. Academy of Management Learning \& Education, v. 2, n. 3, p. 233-249, 2003.

HANSON, Mark. Institutional theory and educational change. Educational administration quarterly, v. 37, n. 5, p. 637-661, 2001.

HASBUN, Tracey Covington; RUDOLPH, Amanda. Navigating the Waters of Accreditation: Best Practices, Challenges, and Lessons Learned From One Institution. SAGE Open, v. 6, n. 2, p. 1-10, 2016.

HARVEY, Lee. The power of accreditation: views of academics. Journal of Higher Education Policy and Management, v. 26, n. 2, p. 207-223, 2004.

HEDMO, Tina. Rule-making in the transnational space: The development of European accreditation of management education. 2004. Tese de Doutorado. Företagsekonomiska institutionen. 
ISTILEULOVA, Yelena; PELJHAN, Darja. How accreditation stimulates business school change: evidence from the Commonwealth of Independent States. Dynamic Relationships Management Journal, v. 2, n. 1, p. 15-29, 2013.

ISTILEULOVA, Yelena; PELJHAN, Darja. Institutional Change as a Result of International Accreditation: Business Schools of Lithuania after the Iron Curtain. Economic and Business Review for Central and South-Eastern Europe, v. 17, n. 3, p. 291, 2015.

JULIAN, Scott D.; OFORI-DANKWA, Joseph C. Is accreditation good for the strategic decision making of traditional business schools?. Academy of Management Learning \& Education, v. 5, n. 2, p. 225-233, 2006.

LARSON, Magali S.; LARSON, Magali Sarfatti. The rise of professionalism: A sociological analysis. Univ of California Press, 1979.

LEJEUNE, Christophe; VAS, Alain. Organizational culture and effectiveness in business schools: a test of the accreditation impact. Journal of Management Development, v. 28, n. 8, p. 728-741, 2009.

MILES, Morgan P.; FRANKLIN, Gerard McClure; HERIOT, Kirk; HADLEY, Linda; HAZELDINE, Mary. AACSB International's 2013 accreditation standards: Speculative implications for faculty and deans. Journal of International Education in Business, v. 7, n. 2, p. 86-107, 2014.

NORTH, Douglas C. Institutions, institutional change and economic performance. Cambridge university press, 1990.

PERTSCHY, G. L. Os desafios para uma gestão eficaz e competitiva no âmbito das instituições de educação superior. In: Encontro Nacional dos Cursos de Graduação em Administração, 17, São Luis: ENANGRAD, 2006.

ROLLER, Robert H.; ANDREWS, Brett K.; BOVEE, Steven L. Specialized accreditation of business schools: A comparison of alternative costs, benefits, and motivations. Journal of Education for Business, v. 78, n. 4, p. 197-204, 2003.

SANYAL, Bikas C.; MARTIN, Michaela. La financiación de la educación superior: perspectivas internacionales. La educación superior en el mundo 2006: la financiación de las universidades, 2006.

SCOTT, W. Richard. Institutions and organizations. Thousand Oaks, CA: Sage, 1995.

SILVA, Márcia Z. Gerenciamento de riscos corporativos sob o enfoque da teoria contingencial: estudo de caso em uma organização hospitalar. Tese (Doutorado em Ciências Contábeis e Administração). Universidade Regional de Blumenau: Blumenau, 2013.

TACHIZAWA, Takeshy; ANDRADE, Rui O. B. Gestão de instituições de ensino. 4. ed. Rio de Janeiro: Editora FGV, 2006. 
TOLBERT, P. S.; ZUCKER, L. G. The institutionalization of institutional theory. Studying Organization. Theory \& Method. London, Thousand Oaks, New Delhi, p. 169-184, 1999.

YIN, R. Estudo de caso: planejamento e métodos. $5^{\text {a }}$ ed. Porto Alegre: Bookman, 2015.

ZAMMUTO, Raymond F. Accreditation and the globalization of business. Academy of Management Learning \& Education, v. 7, n. 2, p. 256-268, 2008.

ZHAO, Jun; FERRAN, Carlos. Business school accreditation in the changing global marketplace: A comparative study of the agencies and their competitive strategies. Journal of International Education in Business, v. 9, n. 1, p. 52-69, 2016. 